\title{
Initial Analysis on the Improvement of Highway Slop Landscape Based on the Ecological Protection
}

\author{
Luo Aidao ${ }^{1, \text { a }}$, Zongling Yan ${ }^{2, \mathrm{~b}}$ and Wenguang Zhai ${ }^{3, \mathrm{c}}$
}

\author{
1. Guangzhou Daguang Expressway Co., Ltd. Guangzhou, 510050; 2.China;China Merchants \\ Chongqing Communications Research and Design Institute, Ltd. Chongqing, 400067. China
}

Key words: highway; slope; ecological protection; landscape improvement

Abstract: On the basis of discussing the connotation of slope ecological protection, this paper put forward the influence of highway construction on ecological environment and the thought in landscape improvement. 19 kinds of technological principles, technical features, scope of application and landscape effects were analyzed and compared. Plant selection and collocation methods on ecological protection were given. The paper has a guiding role in highway slope protection, road-region ecosystem restoration and landscape improvement.

\section{Preface}

Natural landscape was destroyed and the ecological environment was affected by rapid development of Chinese highway construction. Technicians often focus on the feasibility of technical, safety, comfort, speed, ignore environmental factors and ecological problems about highway slope. Moreover, the lack of ecological and social benefits of long-term consideration result in the slope collapse, landslide, debris flow and other serious geological disasters. Thus, the operating cost increases significantly. The harmony between highway and ecological environment should be paid more attention, and reasonable treatment measures should be proposed.

The long-term practice has proved that although the mode of traditional engineering protection can play a role in the treatment and reinforcement of the slope, but it isn't good for environmental protection and ecological balance.

\section{Connotation of slope eco-protection}

The slope eco-protection is a protective measure for the self-circulation of matter and energy, which practice system ecology theory that makes stable material circulation and energy flow engineering-oriented to restore stable producers, consumers and decomposers in damaged highway slope ${ }^{[1]}$. Specifically, slope eco-protection use plants only or combine with no-living materials to replace traditional engineering protection, which adopts the method of adhesion between the roots and the soil, and the interaction between rhizomes to improve the anti-scour and anti-erosion ability. Ecological Technology revetment plays a role in protecting and strengthening slope, meanwhile, restoring and improving Ecological Environment along the highway. The technology can not only demine soil erosion, prevent landslide and debris flow effectively, but also improve natural landscape and guarantee safe driving. It has good economic benefits, social benefits and ecological benefits. 


\section{The influence of highway construction on ecological environment and the ideas of landscape beautification}

\section{The influence of highway construction on ecological environment}

The impact on soil erosion

(1) Earthwork excavation will cause failure to the original geomorphology in highway construction, leading to barrens obviously, earth's surface will be affected by rainfall erosion, surface runoff seriously.

(2) Mishandled, the waste slag caused by heavy rains may result in new soil erosion.

(3) The temporary construction facilities, for example, casting yard, can destroy the original vegetation, result in soil erosion.

The impact on geological hazard

Geological hazard, such as, slope collapse, landslide and mud-rock flow etc. will appear during the construction and operation of highway ${ }^{[2]}$. Series of new geological hazard appear due to high filling and cutting of roadbed which influence the original geological structure could emerge along with soil erosion.

The impact on ecosystem

Some highway cut off the living area of the animals around the road, and changed their life path and living environment, and may even lead to the extinction of some rare animals ${ }^{[3]}$.

\section{Ecological protection and the ideas of landscaping}

Safety, comfort, economy and durable are emphasized in new conception of highway construction. The concept of ecology, environmental protection, green and beautification should be introduced in planning and construction of highway. This is a new reflection of the mind of sustainable development in highway construction. The beautification and promotion of landscape should be considered by decision-maker and engineering designer.

Landscape beautification emphasizes that the highway should have a highly coordination with natural environment around the road and meets the requirements of dynamic and static vision, meanwhile, maintains the harmony of ecological environment. There are some functions of landscape beautification as following:

(1) Avoid driving fatigue and improve driving safety;

(2) Improve the monotonous landscape originally;

(3) Helpful to recover natural environment and maintain ecological balance;

(4) Contribute to water conservation in order to avoid the occurrence of geological hazard;

(5) Helpful to reduce noise pollution and purify air.

\section{Form and comparison of eco-protection for highway slope}

In recent years, with the acceleration of the process of highway construction, ecological technology has been widely used, and the form of protection is also increasing. According to different standards, the eco-protection can be divided into the following types: 


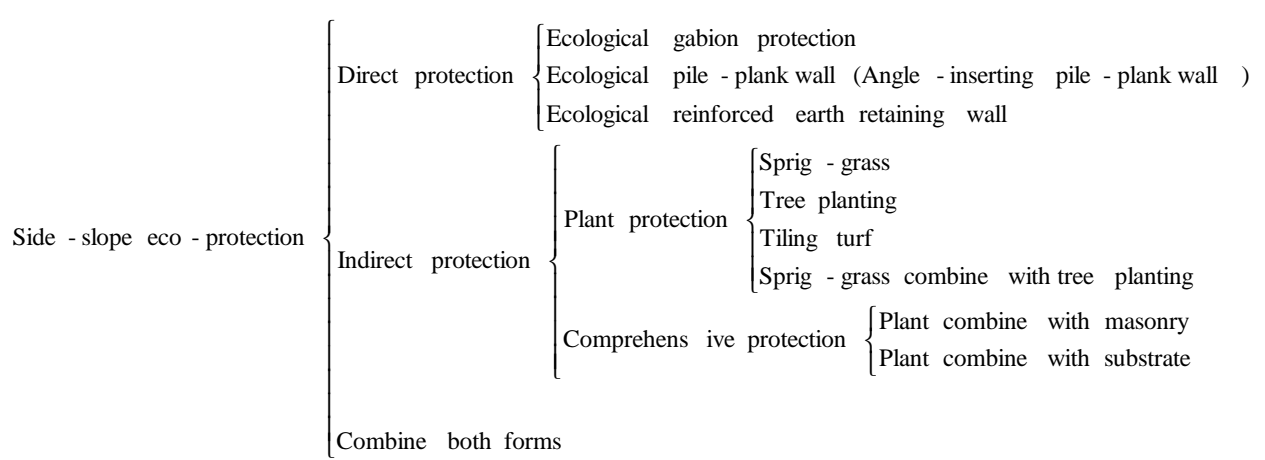

Figure1 Classification of slope eco-protection (based on function of protective structure)

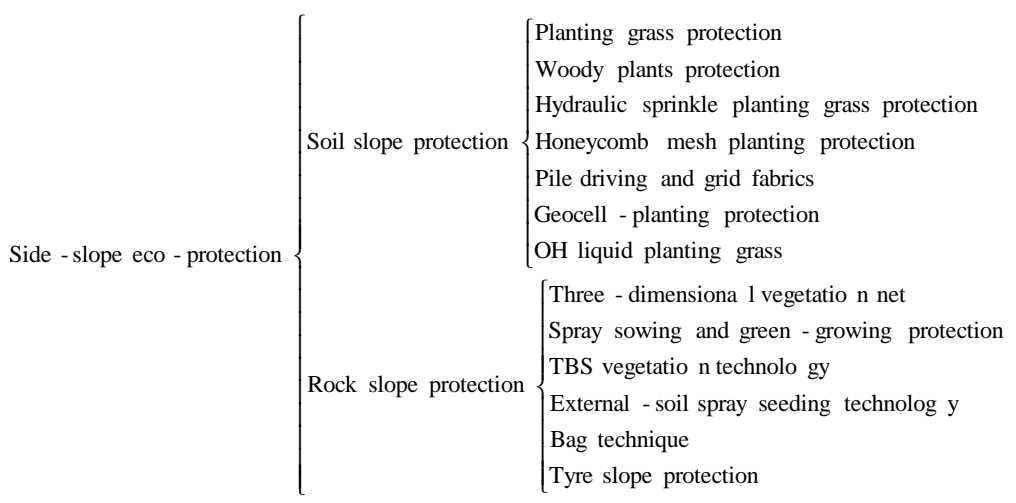

Figure2 Classification of slope eco-protection (based on the type of rock and soil)

(1) Planting grass protection

It's a traditional slope ecological protection measures, which distribute grass seed over the slope, mainly rely on root and soil adhesion to consolidate soil. This method has the advantages of simple construction, but the seeds easily washed, and results in lower survival rate. Therefore, this method often creates a series of slope diseases and the later maintenance cost is high.

(2)Tiling turf

It is a kind of traditional ecological protection slope measures, which laying natural grass or grass-blanket to the surface of the slope directly. This method has the advantages of short duration, simple construction and low cost, but it is easy to be affected by various natural disasters in the prophase.

(3) Woody plants protection

The protection effect of woody plants alone is poor, and the mixed sowing combination method of "arbor + shrub + herb" or "shrub + herb are often used. It is used in such a hybrid method for slope protection. This method can increase the level of community structure. Each species has complementary advantages, promoting the biological diversity and playing a role in lasting protection.

(4) Three-dimensional vegetation net

This method bases on three-dimensional vegetation net as the reinforced material for holding the soil and preventing erosion, providing space for plant growth. The method is simple and has good properties, which can meet the needs of some fast slope protection projects.

(5) Vegetation belt protection

The vegetation belt was fixed on the slope, which has grass seeds, fertilizer, water retaining agent, etc. Its characteristic are: low maintenance cost, uniform seeding and high germination rate, rapidly greening and the formed turf is beautiful.

(6) Hydraulic sprinkle planting grass protection 
The seeds, fertilizer, adhesive, paper pulp, soil improvement agent, pigment were mixed and stirred according to a certain proportion, then injected to the slope surface by mechanical pressure

${ }^{[4]}$. Advantages: the high degree of mechanization and construction speed, easy to survive, green effectively. Disadvantages: Nutrient soil mixed complex, high - quality requirements.

(7) Spray sowing and green-growing protection

Spraying the planting base material into the slope, the plant relies on the "substrate" to grow ${ }^{[4]}$. Its characteristics are: high degree of mechanization, quick turf formation, good protective effect, wide application range and low cost.

(8)Bag technique

Putting seeds in the middle of the two-layers of non-woven fabrics, and then made of straw which filled with soil to form vegetation ${ }^{[5]}$. The technology is simple, with low cost. But the idiot is susceptible to soil and water erosion, and landscape effect is not obvious.

(9)TBS vegetative technology

Using the modified concrete-injection machine to spray base material mixture into the rock slope, and achieve the purpose of protecting and improving the ecological environment ${ }^{[6]}$. With wide application, this method can effectively restrain the soil erosion. Compared with the traditional slope protection technology, it can save investment about $20 \%$.

(10) External-soil spray seeding technology

It can be applied to the slop, which the green effect is poor under normal conditions, or even the special slop that do not have growth conditions. Its characteristic is: high viability, quickly cover the surface of the slope, good protection effect; higher economic benefits and ecological benefits

(11) Honeycomb mesh planting protection

Brick concrete box can effectively reduce the raindrops hitting effect, which reduce the slope surface water flow rate, and avoid scouring, protect the grass to grow. Disadvantages: the cost is higher, solid soil effect is relatively poor.

(12) $\mathrm{OH}$ liquid planting grass

$\mathrm{OH}$ liquid diluted with water according to certain proportion with seed spraying in the slope, grass were planting into the elastic solid film ${ }^{[7]}$. The construction method is simple, and don't need later maintenance, and the greening effect is good. But the engineering cost is higher, limiting its popularization and application.

(13) Pile driving and grid fabrics

Driving the budding stakes into the soil, and make bamboo, PE, barbed wire and other materials into grid, then adopting spray planting method or vegetative belt method to cover slope ${ }^{[8]}$. Wooden itself can sprout, growth, and it also has the function of solid earth and green.

(14) The vines

Through excavation, plant vines and to cover the blunt masonry body, achieve the goal of slope protection and beautify the environment. Advantages: convenient construction, low cost, fast slope protection. But communities are unsteadiness, with low ecological benefits.

(15) Ecological gabion

On the basis of traditional stone cage protection, to fill soil in the gap between the stones, planting seed, provide growth space for plant. No need for heavy machinery and skilled construction personnel. The stone cage is permeable, without setting up drainage facilities. The mesh structure can provide conditions for the growth of plant, maintain the natural ecological environment, and thus more harmonious with the surrounding landscape ${ }^{[9]}$.

(16) Ecological vegetation carpet 
The technology is simple, construction is convenient; and the scouring resistance and corrosion resistance is strong. The raw materials are mainly come from waste straw, which is economic and environmental protection.

(17) Geocell-planting protection

Features: Geocell connection is convenient, with fast construction. Due to the restriction of lattice sheet, the influence of slope runoff and water flushing action were decremented to a certain extent, keeping the soil in place.

(18) Tire slope protection

Put discarded tires on slope surface, fixed, covering with new soil, and then sow or plant in the middle of the tire position. Its characteristic is: "recycling waste material", has the good economic efficiency, environment friendly. Advantages: large amount of solid soil, good water-keeping property ${ }^{[10-11]}$.

(19) Grass technology

Its characteristic are: simple process, convenient construction, but the growth of plants and distribution is not uniform, and ability of resisting rain and soil erosion is poor, the later maintenance cost is high.

According to the above standard, process principle, technical characteristics, scope of application and landscape effect of 19 kinds of common ecological protection technique are compared and a3 summarized.

Table 1 Comparison of 19 kinds of ecologic protection ways for slope

\begin{tabular}{|c|c|c|c|}
\hline $\begin{array}{l}\text { Sequence } \\
\text { numbers }\end{array}$ & The form of protection & Scope of application & $\begin{array}{c}\text { Landscape } \\
\text { effect }\end{array}$ \\
\hline 1 & Planting grass protection & The soil slope with slower slope ratio and lower height & General \\
\hline 2 & Tiling turf & $\begin{array}{l}\text { The soil slope with slope ratio slower than } 1: 1 \text { and strongly weathered soft } \\
\text { rock slope }\end{array}$ & General \\
\hline 3 & Woody plants protection & The soil slope with the ratio slower than $1: 1.5$ & Excellent \\
\hline 4 & $\begin{array}{c}\text { Three-dimensional } \\
\text { vegetation net }\end{array}$ & $\begin{array}{l}\text { Sandy soil, soil-rock and weathered rock slope, with the ratio slower than } \\
\qquad 1: 0.75\end{array}$ & Excellent \\
\hline 5 & Vegetation belt protection & The soil slope with slower slope ratio, weathered rock and sandy slope & Good \\
\hline 6 & $\begin{array}{l}\text { Hydraulic sprinkle planting } \\
\text { grass protection }\end{array}$ & $\begin{array}{l}\text { The slope with the ratio slower than } 1: 1.25 \text { and the soil slope with lower } \\
\text { height }\end{array}$ & Excellent \\
\hline 7 & $\begin{array}{l}\text { Spray sowing and } \\
\text { green-growing protection }\end{array}$ & The rock slope with the ratio slower than 1:0.75 & Good \\
\hline 8 & Bag technique & The rock slope with deeper slope ratio & General \\
\hline 9 & TBS vegetative technology & The hard-rock slope with slower slope ratio & Excellent \\
\hline 10 & $\begin{array}{l}\text { External-soil spray seeding } \\
\text { technology }\end{array}$ & The rock slope with gradient slower than $70^{\circ}$ or the hard-soil slope & Excellent \\
\hline 11 & $\begin{array}{l}\text { Honeycomb mesh planting } \\
\text { protection }\end{array}$ & Side soil slope of embankment & Good \\
\hline 12 & $\mathrm{OH}$ liquid planting grass & Steady soil slop & General \\
\hline 13 & $\begin{array}{l}\text { Pile driving and grid } \\
\text { fabrics }\end{array}$ & The fill slop with gradient slower than $45^{\circ}$ and soil excavation slope & Excellent \\
\hline 14 & The vines & Soil slope, rock slope, soil-rock slope and high-deep slope & Good \\
\hline 15 & Ecological gabion & $\begin{array}{c}\text { The area where the toe of wall be corroded by water and soaking embankment } \\
\text { slope with higher requirements for landscape }\end{array}$ & Good \\
\hline 16 & $\begin{array}{l}\text { Ecological vegetation } \\
\text { carpet }\end{array}$ & The soil slope and sock slope with the ratio slower than $1: 1$ & Good \\
\hline 17 & $\begin{array}{l}\text { Geocell-planting } \\
\text { protection }\end{array}$ & $\begin{array}{l}\text { The fill slop with the ratio slower than } 1: 1.5 \text { and semi-filling and } \\
\text { semi-excavating soil slope }\end{array}$ & Excellent \\
\hline 18 & Tire slope protection & The rock slope with slower slope ratio & Good \\
\hline 19 & Grass technology & The rock slope with gradient slower than $60^{\circ}$ or soil-rock excavation slope & Good \\
\hline
\end{tabular}




\section{Plant selection for ecological protection of highway side slope}

\section{Principles and requirements of plant selection}

Based on guideline "local conditions", Plants selection and configuration should be adapted to the local natural environment. And pay attention to the coordination and complementarity of interspecific relationships. Thus, the plants should meet the following requirements:

(1) Excellent adjustment ability and highly survival rate;

(2) Well developed root system and good capacity of soil protection;

(3) Easy propagation and plant seeds or seedlings can be obtained easily;

(4) Disease resistance ability and easy to manage.

\section{The plants suitable for slope greening}

(1) The herbs

Herbs are kinds of plants type in the ecological protection of highway slope in China. This kind of plants generally have the advantages of fast growth, developed root system, obviously slope protect effect, conveniently plant and low-cost, etc. It is suitable for the general slope and rock slope. The following plants are usually used in ecological protection of highway slope ${ }^{[12]}$ : Trifolium repens, Coronilla varia, Fescue, etc.

(2) The shrubs

Mixing planting between herb and shrub plants has complementary advantages, which was often used to protect the slope. The main protection is herb plants in the early stage, and the shrubs in the later. The following plants are usually used in ecological protection of highway slope ${ }^{[13]}$ : Lespedeza, Amorpha fruticosa, Weigela, etc. The way is suitable for the soil slop, which characterized by high-steep, susceptible to erosion and weathering.

(3) The arbors

Arbors plants have the functions: water-conservation, windbreak and sand fixation, soil-conservation, air-purification, resources-reserve. The way is suitable for the soil slop, strong weathered rock slop, or the slop where there are mountains, hills and forests ${ }^{[14]}$.

(4) The lianas

Lianas plants have a strong adaptability to the rock slope, soil-rock mixture slope and the high-steep slope. The following plants are usually used: Boston ivy, Hedera helix, Kudzu, etc.

\section{Concluding Remarks}

Although the concept and technology of ecological protection has been gradually deepened in highway construction, there are still many deficiencies in the research of ecological function design, ecological slope protection technology model and landscape beautification. Ecological protection is not only the slope revegetation, but also should emphasize the restoration and reconstruction of the ecological system, landscape beautification and promotion. Based on ecological protection technology in the analysis of the slope landscape, this paper can provide a reference for highway slope ecological protection and landscape improvement in future.

\section{Acknowledgements}

The authors gratefully acknowledge the financial supports from the National Science-technology Support Plan Projects 2015BAK09B01. 


\section{References}

[1] Hao Yansong, Wang Guobing, Wang Fuxu. Construction and Ecological Evaluation of the Ecological Slope of Expressway in China[J]. Study on Water-Soil Conservation, 2007, 14(4): 257-262

[2] Wang Weidong. Research on Regional Highway Geological Hazard Management and Spatial Decision Support System Based on GIS[D]. Changsha: Central South University, 2009.

[3] Zhoushuai. Prevention and Legal Perfection of Ecological Risk of Medicinal Animal Resources in Traditional Chinese Medicine-Taking the Black Bear in the Living Body as an Example. China Law Society of Environmental Resources Law Research Association( annual meeting ) ( book 2 ) in 2011[C]. 2011: 868-872.

[4] Tan Yuanbo. Development and Application of Green Protection Technology for Railway Subgrade Slope [J]. Journal of Railway Engineering, 2001, 1: 35-40.

[5] Zhao Jingwei, Lu Jianguo, Wang Ronghua. Application Effect of Seven Kinds of Ecological Slope Protection in Highway Slope[J]. Highway, 2006, 1, 201-204.

[6] Wangyuan. Design and Construction of TBS Vegetation Slope Protection for Rock Slope [J]. Technology of Highway and Transport, 2004, 5: 127-129.

[7] Ji Wenli, Li Weizhong, Hao Hongke, etc. Greening Technology and Application in Soil and Water Conservation[J]. Study on Soil and Water Conservation, 2006, 12(6): 150-152, 158.

[8] Huang Qiongbiao. Forest Road Lawm Nursery Engineering Technology in Line with Ecological Engineering[J]. Study on Soil and Water Conservation, 2003, 10(4): 225-230.

[9] Zhang Junbin. Application and Evaluation of Materials of Ecological Engineering in Taiwan[J]. Science of Soil and Water Conservation, 2007, 5(1): 97-104.

[10] Lu Jianguo, Yu Dongmei. Research Summary on the Ecological Protection of Highway Side Slope[J]. China \& Foreign Highway, 2008, 5: 29-32.

[11] Yaoyu, Tan Xinfu. Application of Ecological Protection Technology in Slope Protection of Nanjing-Hangzhou Expressway[J]. Highway, 2005, 3: 89-92.

[12] Wang Ronghua, Zhao Jingwei. Research Progress and Development Trend of Ecological Protection of Highway Side Slope in China[J]. Highway, 2007, 11: 199-202.

[13] Li Jianwei. Research on the Ecological Protection System of the Mountain Highway Slope in Hebei Province[D]. Shanghai: Tongji University, 2007.

[14] Cao Xingsong, Liu Shixiong, Zhang Mengtao, etc. Research on Plant Selection and Configuration of the Ecological Protection of the Soft Rock in the Southwest Red-Bed Soft Rock[J]. Highway, 2013, 3: 191-195. 